\title{
The Contemporary Orientation of AR in Early Childhood Education
}

\author{
Meena Preethi.B, Deena Magdaline.F, Nivetha S.G, Nivethitha. M
}

\begin{abstract}
Nowadays early childhood education establishments are places where kids aren't only taken care of but conjointly where rigorously planned academic activities (based on pedagogical frameworks) are executed. Augmented Reality is being widely enacted in numerous level of pedagogy like higher-level education, secondary education, primary education, and in informal learning. The purpose of this paper is to bring out the present study on AR in early childhood education between 2009-2018. From results it has been noted that around the past 10 years the publications on early childhood education is reduced and found that the foremost reason for implementing $A R$ is to reinforce the act of interest towards education. This paper centralizes on Implementing 'Marker-based' AR in Early Childhood education which would encourage and keep students concentrated in way of learning..
\end{abstract}

\section{INTRODUCTION}

AR(Augmented Reality) may be a variation to visual environments or video game because they are additional unremarkably[1]. It is defined as the system that permits living and non-living objects to remain within the same area and feel like moving in real time [2]. This AR is being widely implemented particularly in medical, training, military, advertising, and recreation. Between these years, AR attracts plenty deal of impression for the researchers in educational field because of its fabulous options and convenience in reinforcing teaching and learning. Options of the automations that accords to Shanghai dialect[3], permits graduate to: (1) learn in 3D bias, (2) omnipresent, collective and placed learning, (3) graduates accepts of presence, instants and also plunge, (4) anticipating which cannot be seen and (5) connecting between the learning. Since AR invokes the above listed features, AR produces brand unique way for education with creating educating expertise incline additional entertaining and interesting. From the above said, nice option AR has created invoking some specific features were it can be invoked in the terrain of education. Because of the options, varied trainers and investigators are coming forward for the usage of the AR specifically in the field of education. In instance, AR will intensify attainments, gives an pathway for interaction, up diagnostic competence. But, most important recognition of the AR is detected as the act of bringing interest towards

Revised Manuscript Received on September 14, 2019.

Mrs.MeenaPreethi.B, Assistant professor: Sri Krishna College of Arts and Science,Coimbatore,Tamil Nadu, India. (E-mail: meenapreethib@skasc.ac.in)

Ms.Deena Magdaline.F, Assistant professor: Sri Krishna College of Arts and Science,Coimbatore,Tamil Nadu, India. (E-mail: nivethasg16mss027@skasc.ac.in)

Ms.Nivetha S.G, Student of IV M.Sc.SS Sri Krishna College of Arts

Ms. Nivethitha. M, Student of IV M.Sc.SS Sri Krishna College of Arts and Science, Coimbatore,Tamil Nadu, India.. articulation, prompt creative thinking conjointly reinforcing and Science, Coimbatore,Tamil Nadu, India.

education; particularly by: (1) entertainment, engrossment and delight [4-6], (2) obligation [7-9], (3) contentment [10$11]$, (4) temperament which is told, (5) offer convinced perspective [12], (6) contemplation [11], and (7) layer of determination [10]. There is very less attention paid to AR in the field of Early childhood education[4],[14-17].This is also being assisted by Chen [12] who concluded the same. Since there is not much research conducted on AR with Early Childhood education this paper will gain more benefits for enhancing attention among the users.

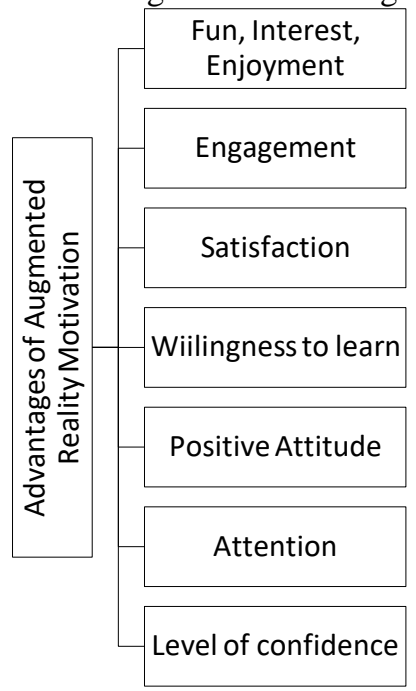

Fig.1 Advantages of augmented reality

\section{PURPOSE}

This paper concentrates firstly, for analyzing extant implementation of AR in ECE pedagogy. According to this, the previously implemented researches will be reviewed and as a result the tremendous prospective of AR shouldn't be atrophied but also be staked with other users.

Secondly, many students have positive impact on Augmented Reality, this paper will report whether there is same benefits for Early childhood education. Finally, this analysis can investigate the foremost used topic that is being inquired, many AR, accessory combined with increased reality application, assortment technique concerned once conducting augmented reality analysis amidst budding learners.

Analysis mission for the AR research is being specified succeededly:

1- Spotting prevailing endeavor of increased reality in infancy discipline.

2- Analyzing benefits in AR for infancy discipline. 
3- Blemishing the foremost topic which is discovered, sorts peculiar to AR, accessory accompanied with increased reality application, analysis samples and therefore the knowledge assortment technique used for increased reality in early childhood education.

\section{EXTANT ENDEAVOR OF AR IN ECE}

From the interpretation of AR in infancy discipline cogitate, establishments like amount as concerns revealed survey is enhanced slowly particularly throughout early 5 years. Conjointly it was being established that no survey was constructed between 2009-2010, very best variety as concerns revealed publications is released only during 2018. This culminates displays infancy analysts have an interest for inspecting about AR options with their benefits about infancy discipline framework. In contempt of this, though many extra researches are found among these past 10 senility, yet amount published isn't abundant. The potential clarification concludes that the technology couldn't abide prepared actuality employed through kids in view of several attitudes of communication, aforesaid trailing and accountant about markers is sorted out[13].

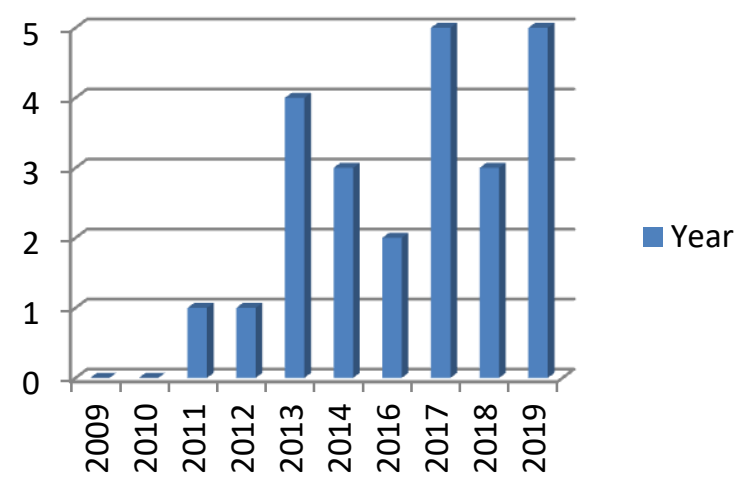

Fig.2 Number of publications related to AR in ECE

\section{LEVERAGE OF AR IN ECE}

Presently, an oversized quantity concerned to printed reviews rumored advantages of AR in education. Despite, their vital urge, about outline as regards to research advantages based on its implementation ECE framework Fig 1 displays conclusion based on the summarized advantages known within the application evaluated. Foremost six benefits of AR: (1) increase achievement / performance / understanding, (2) enhance motivation, (3) develop positive perspectives and behavior, (4) reinforce communal clout, (5) entertainment study including (6) others. Since one study will report over one advantage, therefore, every study will meet over one category. As concluded, The main advantage described within the studies is "enhance motivation" $(28.57 \%)$. AR has been summarized will grab kids attention [18-19], increase kids interest and satisfaction [20]. aside from that, increased reality has been claimed will "increase action / performance /understanding" (26.53\%). On the opposite hand, a few studies rumored on blessings of increased reality in babyhood education like positive attitude, behavior development, psychological feature load and fellow feeling [20-23].

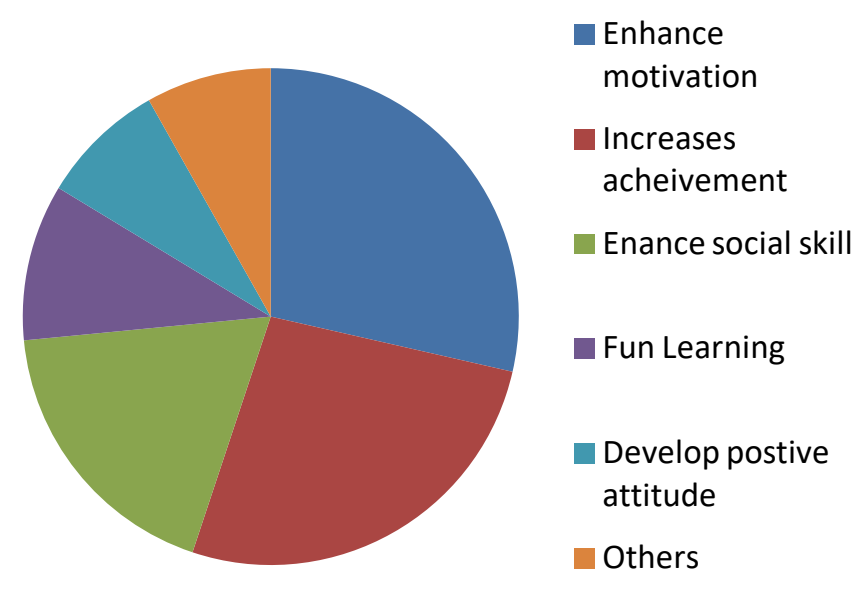

\section{Fig-3 Advantages of augmented reality in the field of ECE.}

\section{MOST USED TYPE OF AUGMENTED REALITY}

There are 3 styles of augmented reality: (1) marker-based augmented reality, (2) marker-less augmented reality including (3) Location AR. Marker-based augmented reality need to use a marker to repair the position of $3 \mathrm{D}$ objects onto real-worlds pictures [28] whereas location based increased reality follows abundant identical method however instead of distinguishing a marker, it assigns digital data to a group of grid coordinates [29]. Based on the review, it's been found that the majority of the analysis used marker-based increased reality $(95.8 \%)$. The potential rationalization for this finding is that marker-based increased reality is easy to use and develop compared to alternative classes. the present of package like Vuforia and Aurasma change the method of making marker-based increased reality. Meanwhile, the least type of AR being utilized is 'Marker-less increased reality' and 'Location based mostly augmented reality' $(0 \%)$. in line with Sirakaya $\&$ Sirakaya [16], this sort of increased reality was used less due to the shortage of professional technique in side of analysts for establishing these applications.

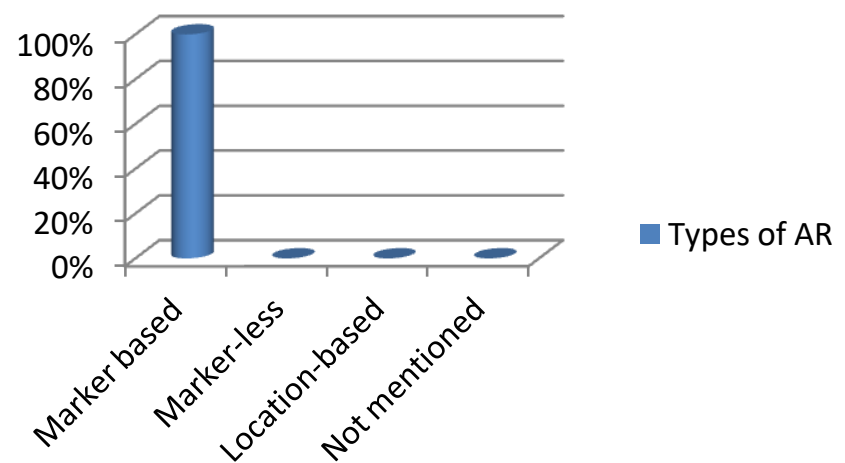

Fig-4 Types of Augmented reality used in ECE. 


\section{MOST USED DEVICE IN AR TECH}

As concluded from the analysis the hand-held devices (42.31\%) like smart phones and tab are utilized more in child discipline survey, continued by 'Surveillance Camera' (30.77\%). Conjoint analysis is being discovered in [16] including [30]. Explanation clearly debits hand-held devices are economically [25], far more lighter and simple to use compared to alternative technology like Head Mounted show (HMD). According, Roberto et al. [26], the long length victimization HMD wouldn't be comfy for children. Gil. [21] has accompanied this, wherever throughout their experiment with augmented reality cluster, they have to carry the HMD as a result of the spectacles are very big according to young users. Scanty researches are performed with totally innovative technologies assisted AR technology like image-projection device and bilateral board.

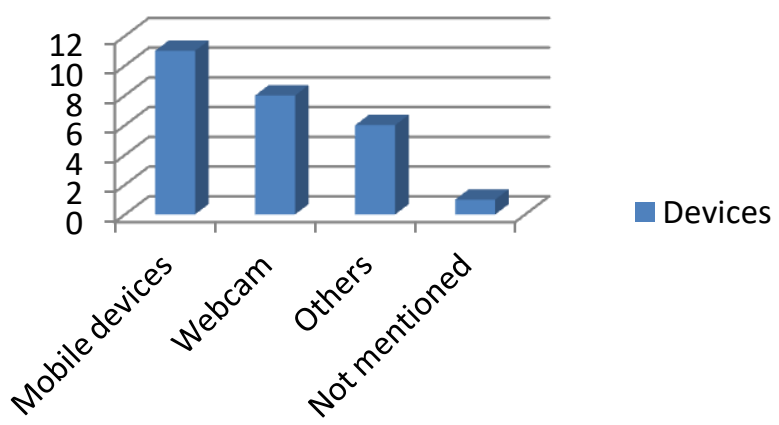

Fig-5 Technology accompanied with AR Technology.

\section{ANALYSIS ELEMENT IN AR}

For the victim analysis, 4 papers were referred based on analysis element, : (1) group of 30 people or small than that, (2) a group of $31-100$ people, (3)a group more than 200 people, and (4) a group with no specific numbers. Conclusion displayed, vast analysis are based on youth youngsters concerned with a group of 30 people or small than that youngsters interior research and no analysis exceeded over a group of 200 people. On point quoted berry[10], Potential comment about those conclusion abide the bigger range for analysis experiment will buildup value by affording technologies like sensible hand-held devices and small hand-held devices for every single member shipment concerned within analysis. Not only this but also one amongst analysis reported 2 totally innovative researches as well as enclosed with two absolutely disparate classes. For then, 5 analysis didn't specificy quantity members participated for analysis along solely ancient kids are provided.

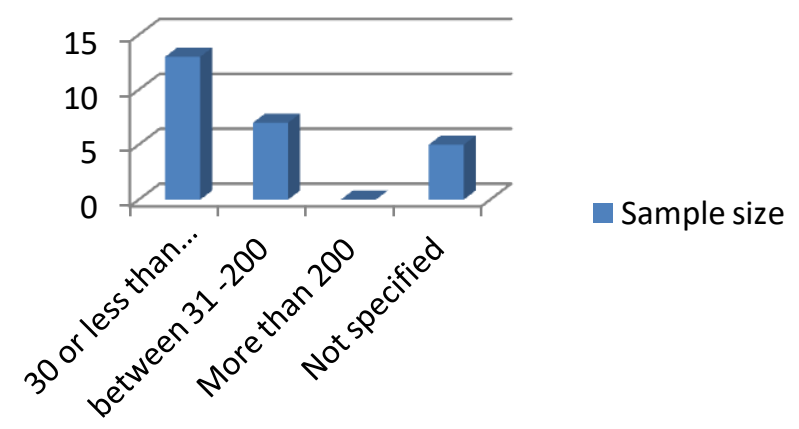

Fig-6 Research Sample

\section{DATA COLLECTION METHORD USED IN AUGMENTED REALITY \& RESULTS}

Fig 7 displays totally contrasting tools which abide for knowledge assortment in AR in babyhood discipline. From the above it is finalized like almost all times accepted knowledge assortment methodology was firstly, 'Test' (33.33\%) secondly 'Observation' (24.44\%). For then, from the research some of few papers adopted 'Others' $(11.11 \%)$ tools[26], article [27] and microcomputers [24]. One study is being allowed for accepting one knowledge assortment methodology, the analysis polls for one league.

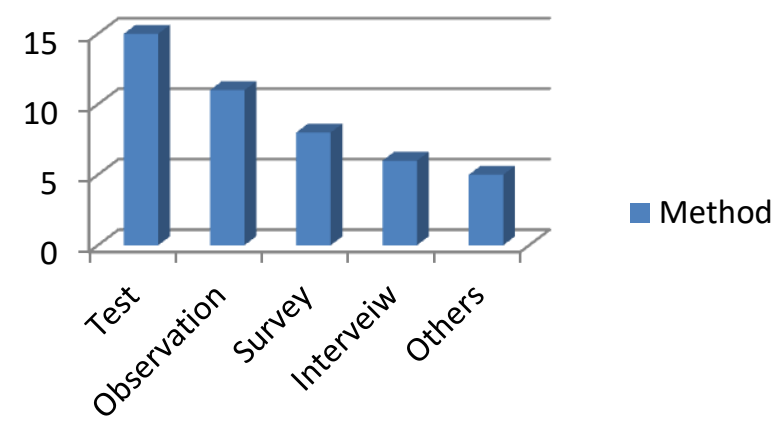

Fig-7 Data collection method

\section{CONCLUSION}

This study has with success investigation in present endeavor of AR in infancy education. From a collection, twenty four analysis are discovered in distinction to varied providers allying IEEE Xplore, Acadamia, Google Scholar. From the supported scrutiny, displays experiments in AR in child education is enlarged since the past few years. Many analyzers specialize in bringing in interest in the young graduates mind and therefore the commonly abided heading was early literacy from research. Marker-based AR and hand-held technology is being opt for wide AR in early childhood education. From the analysis sample smaller amount less than thirty youngsters are mostly participated. Test is being the foremost widespread technology for information gathering functions in AR in infancy discipline. From the report, it summarizes that augmented realty is an proven method with lot more advantages and benefits. The research is being used allusion by alternative researchers in performing researches particularly within AR field by concentrating early children education for the endcustomer.

\section{REFRENCES}

1. Azuma, R. T. (1997). an outline of distended reality. Nearness: Teleoperators and Virtual Environments, 6(4), pp. 355-385.

2. Azuma, R., Baillot, Y., Behringer, R., Feiner, S., Julier, S., and MacIntyre, B. (2001). Late advances in distended reality. IEEE enhancements and Application, 21(6), pp. $34-47$.

3. Wu, H. K., Lee, S. W. Y., Chang, H. Y., and Liang, J. C. (2013). Current standing, openings and difficulties of distended reality in instruction. PCs and instruction, 62, pp. 41-49. 
4. Rambli, D. R. A., Matcha, W., and Sulaiman, S. (2013). Fun learning with zone unit letter set book for instructive organization youths. Procedia innovation, 25, pp. 211219.

5. Gopalan, V. (2016). Associate in Nursing investigation of understudies' inspiration upheld straightforward use, connecting with, pleasure and fun exploitation the distended reality science course book. Revista Delaware la Facultad Delaware Ingeniería, 31(5).

6. Yilmaz, R. M., Kucuk, S., and Goktas, Y. (2017). area unit distended reality image books enchantment or real for instructive institution youths matured five to six? English Journal of tutorial Technology, 48(3), pp. 824 841.

7. Rasalingam, R. R., Muniandy, B., and Rass, R. (2014). investigation the equipment of distended reality innovation in time of life room in Asian country. Diary of examination and strategy in Education (IOSR-JRME), 4(5), pp. 33-40.

8. Jeffri, N. F. S., and Rambli, D. R. A. (2017). vogue Associate in Nursingd improvement of Associate in Nursing distended reality book and transportable application to strengthen the calligraphy steerage for preschool adolescents. Open Journal of sciences, 5(10), pp. 361.

9. Hsu, Y. S., Lin, Y. H., and Yang, B. (2017). impact of distended reality exercises on understudies' STEM intrigue. investigation and apply in Technology distended Learning, 12(1), pp. 2.

10. Bacca, J., Baldiris, S., Fabregat, R., and Graf, S. (2015). Versatile distended reality in skilled making ready and making ready. Procedia innovation, 75, pp. 49-58. The International Journal of sight and sound framework and Its Applications (IJMA) Vol.10, No.6, Dec 2018 fifty seven

11. urban focus, M. E. C., Taketomi, T., Yamamoto, G., Rodrigo, M. M. T., Sandor, C., and Kato, H. (2016) distended reality as interactive media: the case for found jargon learning. examination and apply in Technology distended Learning, 11(1), pp. 4.

12. Chen, P., Liu, X., Cheng, W., and Huang, R. (2017). A Review of exploitation distended Reality in Education From 2011 To 2016. Paper bestowed at Innovations in nice Learning, pp. 13-1. [13] Bacca, J., Baldiris, S., Fabregat, R., and Graf, S. (2014). distended reality inclines in training: a logical survey of examination and applications.

13. Yilmaz, R. M. (2016). tutorial enchantment toys created with distended reality innovation for time of life coaching. PCs in Human Behavior, 54, pp. 240-248.

14. Li, J., van der Spek, E. D., Feijs, L., Wang, F., and Hu, J. (2017). distended reality games for learning: a commentary audit. world Conference on Distributed, Ambient, and Pervasive Interactions, pp. 612-626.

15. Sirakaya, M., and Alsancak Sirakaya, D. (2018). Patterns in tutorial distended reality thinks about: a logical audit. Malaysian on-line Journal of tutorial Technology, 6(2), pp. 60-74.

16. Yilmaz, R. M. (2018). distended reality drifts in instruction somewhere within the vary of 2016 and 2017 years. In N.Mohamudally (Ed.), State of the Art video game and distended Reality Knowhow (pp. 81-97). London: IntechOpen.

17. Sidi, J., Yee, L. F., and Chai, W. Y. (2017). Intuitive english showing studying learning for educational institution consonant-vowel-consonant (CVC) word exploitation distended reality. Diary of Telecommunication, Electronic and computer Engineering (JTEC), 9(3-11), pp. 85-91.

18. Pradibta, H. (2018). distended reality: on a daily basis petitions for nestling understudy. Universal Journal of
Interactive Mobile Technologies (iJIM), 12(1), pp. 151159.

19. Han, J., Jo, M., Hyun, E., and So, H. J. (2015). watching very little youngsters' observation toward distended reality-mixed play. tutorial Technology examination and Development, 63(3), pp. 455-474.

20. Gil, K., Rhim, J., Ha, T., Doh, Y. Y., and Woo, W. (2014). region unit Petite Theater: distended reality storybook for supporting youngsters' individual inclination conduct. blended and distended RealityMedia, Art, scientific discipline, Humanities and magnificence (ISMAR-MASH'D), 2014 IEEE International meeting, pp. 13-20.

21. Bai, Z., Blackwell, A. F., and Coulouris, G. (2015). investigation Flemish-speaking distended Reality: The Fingar Puppet System For Social pretend Play. Paper bestowed at the Proceedings of the thirty third Annual ACM Conference on Human Factors in Computing Systems, pp. 1035-1044.

22. $\mathrm{Pu}, \mathrm{M}$., and Zhong, Z. (2018). Improvement of a Situational Interaction Game for up instructive institution Children' Performance in English-Vocabulary Learning. Paper gave at the Proceedings of the 2018 International Conference on Distance Education and Learning, pp. 8892.

23. Campos, P., Pessanha, S., and Jorge, J. (2011). Encouraging joint effort in educational institution through Associate in Nursing distended reality game. world Journal of video game, 10(3), pp. 33.

24. Yasin, A. M., Isa, M. A. M., and Endut, N. A. (2016) Intelligent prophet's storybook exploitation distended reality. symbolism the since quite whereas past keep running of on-line Learning, pp. 391-399.

25. Roberto, R., Freitas, D., Simoes, F., and Teichrieb, V. (2013). A Dynamic Blocks Platform upheld Projective distended Reality and Tangible Interfaces for tutorial Activities. Paper bestowed at the Virtual and distended Reality (SVR), 2013 XV meeting, pp. 1-9.

26. Ati, M., Kabir, K., Abdullahi, H., and Ahmed, M. (2018). distended Reality distended digital computer helped Learning for Young adolescents. Paper gave at the 2018 IEEE meeting on digital computer Applications and Industrial material science (ISCAIE), pp. 129-133.

27. Ozdemir, M., Sahin, C., Arcagok, S., and Demir, M. K. (2018). The consequence of distended reality applications within the training procedure: a metainvestigation study. Eurasian Journal of tutorial examination (EJER), pp. 74.

28. herring, G., and Rampolla, J. (2013). distended Reality: Associate in Nursing rising Technologies Guide to zone unit. Waltham, USA: Sygress business enterprise.

29. Akçayır, M., and Akçayır, G. (2017). blessings and moves known with distended reality for instruction: a logical audit of the writing. tutorial investigation Review, 20, pp. 1-11. 